\title{
Supervivencias del amor cortés en el bolero hispanoamericano
}

\section{Survival of courtly love in Latin American Bolero}

\author{
Donaji CUÉLLAR \\ (Instituto de Investigaciones Lingüístico-Literarias, \\ Universidad Veracruzana) \\ dcuellar1@hotmail.com \\ ORCID ID: 0000-0002-4104-8321
}

\begin{abstract}
Latin American boleros use poetic RESUMEN: En los boleros hispanoamericanos figures that can be traced in medieval courtly love. existen supervivencias del amor cortés medieval. The topics such as «love service», «love sickness» Los tópicos del servicio de amor, el «mal de and «dying of love», present in the Cancionero amores» y «morir de amor» presentes en el general by Hernando de Castillo (1511) occur in Cancionero general de Hernando de Castillo (1511) boleros from the XXth century. In the present work I también se encuentran en boleros del siglo XX. Se shall establish some links between the Cancionero harán, así, conexiones entre el erotismo del general eroticism and the seductive nature of songs. Cancionero general dirigido a las cortes y los Eventually, I shall define the «hybrid bolero» nobles con el bolero y su apuesta por la seducción. concept.

Todo ello hasta llegar a lo que se propone como boleros llamados «híbridos».
\end{abstract}

KeYwORDS: Courtly love, eroticism, bolero, Latin PALABRAS-ClAVE: amor cortés, erotismo, bolero, America, song books Hispanoamérica, cancionero

Cantar poemas a las damas españolas, desde finales de la Edad Media hasta bien entrado el siglo $\mathrm{XV}$, fue un modo de cultivar la tensión erótica entre los amantes cortesanos que solían profesar amor — de verdad o fingido - sirviendo y favoreciendo a su amada. Fue un modo de enamorar a las damas para conquistar su amor, que no solo entrañó una poética cortés y una estética conceptista que se practicaban en la vida cotidiana, sino también un código de conducta en perfecta correspondencia con el contenido de las canciones, que implicaba el honor del caballero, en cuyo centro reinaba la dama, a quien rendía servicio de amor. Es indudable que el legado del amor cortés, tanto en la lírica como en los rituales relativos al cortejo y a la experiencia amorosa, marcaron profundamente la cultura occidental: su código y algunos de sus rasgos siguen vigentes hasta nuestros días, para bien y para mal.

En este trabajo me gustaría exponer algunas supervivencias del amor cortés en el bolero, un género que comparte con la lírica cortesana hispánica su referencia a la relación erótica entre hombres y mujeres, la invitación a proyectar sus emociones y deseos en las canciones en nombre de la experiencia vivida, y un código de conducta orientado a la conquista de la amada. Se trata de un repertorio de canciones que siguen formando parte del proceso de socialización amorosa entre diferentes clases sociales en Hispanoamérica, por cuanto ha producido prácticas culturales ritualizadas, como la serenata y los bailes, 
que han llegado hasta nuestros días ${ }^{1}$. Para ello reviso tres tópicos frecuentes en las coplas del Cancionero general de Hernando del Castillo ${ }^{2}$ : el servicio de amor, el «mal de amores» y «morir de amor», comparándolos con sus supervivencias en una muestra representativa de veinte boleros hispanoamericanos extraída de tres cancioneros del siglo $\mathrm{XX}^{3}$. La revisión tiene el propósito de advertir las continuidades del bolero respecto del amor cortés, así como las posibles aportaciones del género a la tradición hispánica. Pensé en partir del Cancionero general porque documenta la poesía que se cantaba en las cortes españolas; porque esta lírica, de entretenimiento cortesano, al pasar a la letra impresa, se convirtió en producto venal dirigido a los nobles y en soporte escrito de la educación lírica y sentimental de varias generaciones. Además, fue una de las primeras obras tentativas de esta índole en la cultura europea y conserva el carácter caudaloso y colectivo de las grandes compilaciones poéticas manuscritas del siglo XV (González Cuenca: 3136). La elección del bolero hispanoamericano se debe a que es un género cuyo lenguaje amoroso apuesta por la seducción, y cuyos orígenes corteses ya había advertido Iris Zavala (1991).

De acuerdo con Zavala, en cuanto género cantable y bailable, el bolero, de andaluz, no tiene nada más que el nombre; surgió, como el tango, en el último tercio del siglo XIX en la trova tradicional de Santiago de Cuba, entre 1885 y 1886 (18-19); pronto llegaría a México y a las islas caribeñas y, en viajes de ida y vuelta, se fue enriqueciendo debido al «lenguaje fino y exquisito que americanizó el modernismo al difundirlo» (20). Se trata de un género en el que confluyeron elementos hispanos y afrocubanos; pero en los años veinte del siglo pasado, se enriquecería con los tonos y ritmos de las culturas que lo acogieron; así surgieron el bolero son, el bolero mambo, el bolero feeling y el bolero ranchero, en el que México ocupa un lugar importante.

Este género ha tenido varios momentos claves en su desarrollo. En sus orígenes, el bolero implicó modernismo y modernidad de las nacientes capitales del siglo XIX americano; su lenguaje de seducción y placer formó parte del proyecto modernista hispanoamericano; sus historias de amor revelan su imaginario erótico, sus crónicas amatorias, sus amores idealizados, velados y prohibidos. A finales del siglo XIX, afirma Zavala, la sociedad hispanoamericana sostenía «una especie de torneo ficticio» que tenía por objeto a la mujer. En torno a ella se tejían relaciones «corteses» que eran contrarias a

\footnotetext{
${ }^{1}$ El bolero como práctica ritualizada para la conquista amorosa ha sido ya estudiado por María del Carmen de la Peza Casares (2001), quien asegura que la serenata y el baile forman parte de una tradición aún vigente en la Ciudad de México, cuyos boleros siguen difundiéndose en la radio, especialmente en programas de «música romántica» (8-10). En esta obra la investigadora se ocupa de estudiar la influencia del bolero en la educación sentimental de México.

${ }^{2}$ Para este trabajo empleo la edición de Joaquín González Cuenca (2004) y abrevio CG indicando entre paréntesis el número de volumen seguido del número de copla.

${ }^{3}$ Hasta la fecha únicamente he podido localizar una compilación seria del bolero cubano, realizada por Helio Orovio (1991) y otra de Rodrigo Bazán del bolero en México (2001). Orovio fue un poeta y músico que nació y murió en Cuba (1938-2008). Al parecer, es poco conocido, pues solo he podido encontrar, en El País, La Jornada y El Universal en línea, los datos que aquí proporciono. Es autor del Diccionario de música cubana (Letras Cubanas, 1992), obra a la que le dedicó veinte años, y de Las dos orillas, libro de ensayos (Universidad Veracruzana / Universidad de La Habana, 2002). Incluyo también los boleros que compilaron Mario Kuri Aldana y Vicente Mendoza Martínez (1992) en su Cancionero popular mexicano. En la integración del corpus no quise pasar por alto aquellos boleros que citan las dos únicas estudiosas del género de las que tengo noticia, como emblemáticos del «amor cortés». Por ello he tenido que acudir también a letras que solo he podido encontrar en línea. Debido a la falta de documentación propia de un tema que apenas se empieza a investigar, no siempre me fue posible precisar las fechas en que fueron compuestos los boleros que incluye esta muestra, por lo que indico $\mathrm{ca}$. entre paréntesis, cuando, a partir de la información encontrada en línea o en la bibliografía, calculo las décadas en las que tuvieron mayor difusión y éxito entre el auditorio.
} 
las relaciones permitidas por las instituciones. De ahí que el bolero decimonónico sea un «desbocamiento tolerado» que revela relaciones de poder y una justificación para la seducción $(12,96,103)$. Con el modernismo ${ }^{4}$, el bolero fue escuchado por un público muy amplio: la burguesía que asistía a salones de baile, los trabajadores que llegaban a casa y el pueblo que participaba en las ferias y festividades públicas (19). El bolero como canto cortés a las mujeres surgiría en Yucatán hacia la segunda década del siglo XX; Ricardo Palmerín, Guty Cárdenas, Ricardo López Méndez, Emilio Pardón, entre otros, cantaron la utopía de la bella novia intangible en composiciones de ritmo sensual, como Ojos soñadores, Muchachita que sueña, Muñequita, que lanzaría el Quinteto Mérida hacia 1928. El canto cortés llegaría a los años treinta — década en que el género se disemina y difunde en toda América desde Cuba, México y Puerto Rico ${ }^{5}$ - con Agustín Lara, quien contribuyó a democratizar la cortesía con mujeres pecadoras, perdidas y prostitutas, de indecisas fronteras entre Eva y María, al estilo modernista, creando el bolero de cabaret (37). Durante los años cuarenta y cincuenta se vivió la belle époque del bolero en el Caribe, con Rafael Hernández (Lamento borincano), Toña «la Negra» y Olga Guillot; en México, con Miguel Valladares (Cenizas), Agustín Lara, orquestas, mariachis, tríos, dúos y solos, como Eva Garza, Ruth Fernández, Marco Antonio Muñiz, Joe Valle, Daniel Santos, Bobby Capó, entre otros. El bolero formaba parte de la vida cotidiana en cabarets, salones familiares, casinos, cines y, desde luego, en la radio (44-48).

Por su parte, Peza Casares anota que durante los años cincuenta en México, el agotado bolero de cabaret estilo Agustín Lara se transformó en bolero romántico de trío al recibir el impulso de las innovaciones del trío Los Panchos; «Usted» (1951) de Gabriel Ruiz es representativa de la época (112). En México, los años sesenta fueron invadidos por el rock y la producción de bolero disminuyó, pero con autores como Vicente Garrido Calderón ${ }^{6}$, Armando Manzanero ${ }^{7}$ y Álvaro Carrillo ${ }^{8}$, adquirió nuevos bríos «románticos» y también «rancheros» (113). A finales de la década de los ochenta y al principio de los noventa el bolero vivió su declive y resurgiría a propósito de las celebraciones del centésimo aniversario de nacimiento, cuando empezaron a proliferar espectáculos especiales de este género en el teatro, la radio y la televisión en México y América Latina $(8-9)^{9}$.

\footnotetext{
${ }^{4}$ Durante las primeras dos décadas del siglo XX muchos boleros se basaron en poemas modernistas; predominaron los versos de Amado Nervo, Gutiérrez Nájera, del dominicano Bazil, del venezolano José Antonio Pérez Bonalde, entre otros (31-32).

${ }^{5}$ Aquellos ojos verdes, compuesta por Adolfo Utrera y musicalizada por Nilo Menéndez, Nadie y Sin ti de Agustín Lara, Flores negras del cubano Sergio de Karlo, Perfidia y frenesí, del mexicano Alberto Domínguez son emblemáticas de esa época. En esta década también participaron mujeres como María Grever, Consuelo Velázquez, con Bésame mucho; Tina Polak, con Estoy sola y Solamente una vez; la cubana Isolina Carrillo, con Dos gardenias; y María Alma, con Compréndeme (44).

${ }^{6}$ N. en 1944 en la ciudad de México y m. en Guadalajara el 2003. Su primer éxito fue «No me platiques más» ca. 1950, década en la que se escucharon sus canciones. Intérpretes: Pedro Vargas, Pedro Infante, entre otros. Cf. SACM, en línea.

${ }^{7}$ N. en la ciudad de Mérida, Yucatán el 7 de diciembre de 1935. Su primera canción: «Nunca en el mundo» (comp. en 1950). Llega a la ciudad de México ca. 1957. Sus primeras canciones: «Llorando estoy», «Voy a apagar la luz»... Intérpretes: Lucho Gatica, Pedro Vargas, Carmela y Rafael. Cf. SACM, en línea.

${ }^{8}$ N. en Cacahuatepec, Oaxaca el 2 de diciembre de 1919. Cultivó el bolero romántico moderno. Entre sus composiciones más conocidas: «Sabor a mí», «La mentira» (conocida como «Se te olvida»), «Un poco más», «El andariego», entre otras. Algunos de sus intérpretes: Marco Antonio Muñiz, Pedro Vargas, Frank Sinatra, Doris Day, Los Panchos, Los Duendes, Pepe Jara. Cf. SACM, en línea.

${ }^{9}$ En busca de formas de expresión alternativas a la balada romántica, más comercial y estandarizada, en México, distintos cantantes y compositores han retornado al bolero; recibió un nuevo impulso gracias a intérpretes del canto latinoamericano como Tania Libertad, Guadalupe Pineda y Eugenia León. Luis
} 
Por otro lado, en lo que concierne a la poética cortesana, el amor es concebido como un culto y un servicio, cuyo vasallaje espiritual dignifica al enamorado; la lucha interna y la conducta esquiva de la dama le producen tristeza e inestabilidad, pero él se entrega a su dolor de manera gozosa. Conviene tener presente que, aunque el amor implique toda clase de sufrimientos, el amante conserva una visión gozosa del amor, incluso en la adversidad, pues, como advierte Margit Frenk, el amor se vive como un deseo siempre insatisfecho, que motiva en el amante la vivencia de un permanente estado de sufrimiento que cultiva sin descanso, aunque actualmente nos parezca una conducta masoquista. Esta actitud es parte del código cortesano, donde solo los hombres nobles eran capaces de profesar ese «amor-deseo-pesar» que no rehuía, sino que buscaba la muerte, porque su capacidad de vivirlo así lo ennoblecía más aún (43). De ahí que varias composiciones del Cancionero general expresen que el sufrimiento amoroso es meritorio, como asegura Lope de Estúniga:
A mis cuidados y males
el mayor descanso es
pensar lo que vos valés.
Y con esto que vos siento
vivo, ipar Dios!, tan pagado
que el mi afán y mi tormento
dólo por bien empleado,
y a mis cuidados y males
el mayor descanso es
pensar lo que vos valés
$\left(C G, 1, \mathrm{n}^{\mathrm{o}} 82 / 1\right)^{10}$.

Por su parte, el conde de Ureña agrega que sufrir es loable incluso si la dama prefiere a otro amante; sugiere no renunciar al amor, dejando su corazón a la amada en calidad de prisionero de su amor:
Pues quisisteis ser agena
mis servicios desechando, partiré, triste, llorando vuestra culpa con mi pena. Partiré con gran tristor del cuidado que me distes, quexoso porque hezistes de mis placeres dolor. Mi corazón en cadena vos dexo, por mí quexando la partida que, llorando, vuestra culpa con mi pena $\left(C G, 4, \mathrm{n}^{\circ}{ }^{\circ} 49\right)$

El tópico del «mal de amores» ofrece varias versiones complementarias en las coplas revisadas. Para Lope de Sosa, consiste en una constante desdicha causada por emociones contradictorias asociadas con el deseo de morir constantemente de amor más

\footnotetext{
Miguel, por su parte, contribuye mucho en el circuito comercial y el mismo Juan Gabriel aportó al género bolerístico algunas composiciones $(113,9)$.

${ }^{10}$ Como sabemos, es usual en la poesía de cancionero encontrar varias versiones sobre un mismo tema. Otra variante del sufrimiento meritorio se encuentra en el número 82/2.
} 
allá de la muerte, por parte de un amante que sabe que su «mal» no tiene remedio, y cuyo dolor y desdicha le dan sentido a su vida ${ }^{11}$. De acuerdo con Gonzalo de Tapia, este mal se manifiesta con dolores del cuerpo y del alma causados por el desamor ${ }^{12}$. Desde la visión hiperbólica de Hernán o Rodrigo de Mexía, el dolor que produce el mal es agudo y crónico, además de que causa afición en el amante ${ }^{13}$. Asegura Gonzalo de Tapia que ese mal no tiene remedio, aunque cambie de objeto ${ }^{14}$. Quizá por ello Pedro Leonardo de Avendaño aconseja la resignación y la conservación de la esperanza en que cambie la suerte del sufriente o, en otras palabras, en que acepte su destino ${ }^{15}$.

Las actitudes del amante cortés ante el «mal de amores» a menudo se orientan a reafirmar su voluntad de sufrir incluso, como ya se dijo, hasta la muerte, lo cual, en versión de Íñigo de Velasco, implica la elección de su propia «perdición», entendida como una pasión desenfrenada que conduce al amante, al mismo tiempo, al erotismo y la muerte $^{16}$. Así pues, «perderse» en ambos es la ferviente divisa de los poetas que escribieron versos relacionados con este padecimiento, con más conceptismo que emotividad, incluso si se tratase de una perversa hechicera cuyas yerbas produjeran la tristeza y el dolor del amante, como indica socarrona e hiperbólicamente una copla de Pedro Fajardo ${ }^{17}$. Veamos ahora cómo sobreviven estos tópicos en nuestro corpus.

En el bolero hispanoamericano, el tópico del servicio de amor alberga las contradictorias emociones del amante cortés. «Juramento» (ca. 1920-1930) del cubano Miguel Matamoros ${ }^{18}$ es una composición de tono melancólico que podemos considerar como el ars amatoria del bolero hispanoamericano, que consiste en resistir los

11 «Mucho mal está mi mal / que en desdicha se convierte, / pues se le niega la muerte / por hazello más mortal. / Porque no falte dolor, / el dolor me tiene bivo: / grande es el mal que recibo / y el desconsuelo es mayor, / pues con dolor desigual, / porque en remedio no acierte, / detiene mi mal la muerte, / mas no la muerte a mi mal» $\left(C G, 2\right.$, n. $\left.^{\circ} 290\right)$.

12 «QQueréis mis males sabellos? / Quando el mal es mal de amor, / si el cuerpo tiene un dolor, / el alma mis cuentos dellos. / Son del cuerpo los dolores / que pueden tener mudanca; / los del alma son de amores / y sin ninguna esperanca. / Mas, pues vuestro desamor/ es la causa de tenellos, / el del cuerpo no es dolor/ quando el alma muere de ellos» $\left(C G, 2\right.$, n. $\left.^{\circ} 298\right)$.

13 «Mucho me duele mi pena / y mi mal mal me lastima, / pues no he visto un ora buena/ después que passó la prima. / Con este mal que posseo, /de bevir tengo temores, / pues me queda el desseo/ por pena de mis dolores. / Y con esto se condena/ mi coraçon y lastima, / pues todas las oras pena / después que passó la prima» $\left(C G, 2, \mathrm{n}^{\circ} 334\right)$.

14 «Ninguno tenga esperanca / que en el mal de amor hay medio, / porque es cierta su mudanca / y es incierto su remedio. / Y si Amor y su belleza / os hiziere amar forçado, / no os dure más el cuidado/ que le dura la firmeza. / No os engañe su esperança, / que al comienco, al fin y medio/ es muy cierta su mudança

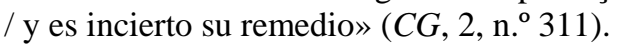

15 «Quien por libre no se tiene / sufra y pene con cordura, / que en la guerra de Tristura, / quando más contraria viene, / se suele mudar Ventura / El bevir desesperado/ por libertad cativa/ espera ser remediado / teniendo la vida biva. / Y, pues esperanca tiene, /sufra su mal con cordura, /que en la guerra de Tristura, / quando más contraria viene, / se suele mudar Ventura» $\left(C G, 2\right.$, n. $\left.^{\circ} 313\right)$.

16 «De nuevo quiero firmarme / en seguir mi fe muy firme / que del mal que ha de venirme / yo no entiendo arrepentirme. / ¡Ved cómo podré apartarme! / Y con esta condición, / viendo presentes mis males, / contra mis malas señales / escogí mi perdición; / porque sólo en acordarme/ que vuestro puedo dezirme, / ¿qué muerte puede venirme/ que no gane yo en morirme/ más que no vos en matarme?» $\left(C G, 2\right.$, n. $\left.^{\circ} 306\right)$.

17 «Tú eras, serás y eres / la que amo sin fengir / y, aunque alexas mis plazeres, / todo lo quiero sofrir: / amarga cuanto quisieres. / Esta yerva que me viste / tan amarga la gusté / que creo tú la troxiste / por hazerme siempre triste, / y a todo basta mi fe. / De mortal dolor me hieres, / al qual no quiero huir, / que, si nunca te dolieres, / todo lo entiendo sofrir / y ¡amarga quanto quisieres!» (CG, 2, n. $\left.{ }^{\circ} 324 / 2\right)$.

${ }^{18}$ N. en Santiago de Cuba el 8 de mayo de 1894 y m. el 15 de abril de 1971 en la misma ciudad. Director del famoso trío que llevó su nombre (Cf. Orovio, 1991: 37). El 8 de mayo de 1925 fundó el trío Matamoros con Rafael Cueto y Siro Rodríguez. Cf. EcuRed, en línea. El primer disco del trío data de 1928. Cf. CiberCuba, en línea. 
sufrimientos propios del amor sin padecerlos, sino gozándolos y exaltándolos ante la amada:
Si el amor hace sentir hondos dolores y condena a vivir entre miserias yo te diera mi bien por tus amores hasta la sangre que hierve en mis arterias.
Si es surtidor de místicos pesares, si hace al hombre arrastrar varias cadenas yo te juro arrastrarlas por los mares infinitos y negros de mis penas (EcuRed, en línea).

En «Toda una vida» ( $c$ a. fines de los años 30 y 40), del cubano Osvaldo Farrés ${ }^{19}$, el servicio de amor radica en la propuesta del amante de servir a la amada toda una vida para mimarla y cuidarla, a pesar de que le produzca emociones negativas como «ansiedad, angustia y desesperación». «Obsesión», compuesta en 1947 por Pedro Flores (Bazán, 2001: 136), uno de los mejores compositores portorriqueños ${ }^{20}$, propone una poética cortés, que consiste en concebir la pasión amorosa como una obsesión entre un hombre y una mujer, y el amor como el alimento de la vida y como la ración de paraíso ofrecida por la divinidad. La composición es al mismo tiempo una declaración de amor cortés por cuanto el amante está dispuesto a vencer todos los obstáculos que le imponga el destino para conquistar a su amada ${ }^{21}$. En «Amor ${ }^{22} »$, del mismo Flores, este se experimenta como una fuerza transfiguradora de la realidad, que se presenta bella y dulce al enamorado: torna «rosa todos los colores y habrá miel en todos los sabores»; se concibe como «el milagro de la vida» que impacta en el alma y «llena de ansiedad» el corazón. También es una declaración de amor que revela la servidumbre del hombre hacia la mujer, por cuanto le expresa su veneración para obtener su amor:

Amor yo te profeso prenda amada, apiádate de mí, dame tu amor.

${ }^{19}$ N. el 13 de enero de 1902 en Quemado de Güines, Cuba y m. el 22 de septiembre de 1985 en New Jersey, Estados Unidos. (Cf. Orovio, 1991: 96). Uno de los más importantes músicos cubanos; desde 1962 salió de Cuba para residir en New Jersey. En 1950 fue nombrado miembro de la Sociedad de autores, compositores y editores de música de París (SACEM). Su primera composición, la guaracha «Mis cinco hijos», data de 1937. Ha tenido intérpretes latinoamericanos, norteamericanos y hasta una francesa; entre ellos: Pedro Vargas, Toña La Negra, Marco Antonio Muñiz; Nate King Cole, Bring Crosby, Edith Piaff. Cf. EcuRed, en línea.

${ }^{20}$ N. en Naguabo, Puerto Rico el 9 de marzo de 1894. En los años 20 del siglo pasado se fue a vivir a Nueva York, donde conoció a Rafael Hernández. Hacia 1930 integró el Cuarteto Flores, grupo con el que empezó a grabar sus canciones. Más tarde abandonó el Cuarteto y fue a radicar a México, luego a Cuba y, finalmente, regresó a Nueva York, donde fundó un nuevo cuarteto que incluía a Daniel Santos. Murió en julio de 1979. Cf. Bailyn, en línea.

${ }^{21}$ «Por alto está el cielo en el mundo / por hondo que sea el mar profundo, / no habrá una barrera en el mundo / que mi amor profundo / no rompa por ti / Amor es el pan de la vida, /amor es la copa divina, / amor es un algo sin nombre / que obsesiona a un hombre/ por una mujer. / Yo estoy obsesionado contigo, / Y el mundo es testigo / de mi frenesí / Por más que se oponga el destino/ serás para mí» (Bazán, 2001: 136).

22 Todas las citas de este bolero provienen de una interpretación en voz de Daniel Santos (Youtube, en línea). 
«Entrega total» (1963) del michoacano Abelardo Pulido ${ }^{23}$, bolero ranchero cuya fama internacional se debe a la voz de Javier Solís, es una contundente declaración de amor de la más alta cortesía. El amante, al no soportar la ausencia de la amada, se pone a su merced para que ella haga con él lo que quiera, sea para bien o para mal, pues lo que le interesa es conservarla ${ }^{24}$. «Persistiré» del cubano Rubén Rodríguez ${ }^{25}$ es un bolero que propone una poética del enamorado muy cercana al amor cortés, pues se trata de un amante que no renunciará nunca a la conquista de su amada, a pesar de los obstáculos impuestos por la sociedad y también piensa que su dolor lo dignificará:

\title{
Persistiré \\ aunque me auguren una gran desilusión, hay que enfrentarse a la vida con valor, vale la pena sufrir por este amor (Orovio, 1991: 260).
}

Aunque en el bolero hispanoamericano no hay conceptos ni creencias asociados con el antiguo «mal de amores», los intérpretes aseguran que el amor a menudo genera padecimientos que cantan a la amada en varios tonos con el propósito de conquistarla. El contenido de los siguientes ejemplos se orienta a formular declaraciones de amor, expresar las contradicciones propias de la pasión y suscitar el deseo de la amada. Pero los síntomas que padece el enamorado ya nada tienen que ver con dolores del cuerpo y del alma, sino con las penas emocionales que desata la pasión sexual ante la ausencia de la amada (Nota contenido erótico Poesía de Cancionero y epígrafe del General).

Por ejemplo, «Usted» (ca. 1920-30), del yucateco José Antonio Zorrilla Martínez ${ }^{26}$, despliega síntomas muy parecidos a los del antiguo «mal de amores» en voz de un amante que se auto-caracteriza como «esclavo» de los ojos de la mujer y «juguete de su amor». Estos síntomas, desdicha, aflicción, desencanto, desesperación y pérdida de la razón, son causados por los vaivenes de la voluntad de una mujer caprichosa que «juega» con sus «penas» y «sentimientos», los cuales son sufridos con resignación y esperanza, como en la poética cortés:

\author{
Usted me desespera \\ me mata, me enloquece, \\ y hasta la vida diera \\ por vencer el miedo \\ de besarla a usted
}

(Kuri Aldana, 1992, 2: 232-233).

${ }^{23}$ N. en Villa Venustiano Carranza, hoy San Pedro Caro, Michoacán, el 5 de mayo de 1933. En 1941 llegó a la Ciudad de México y más adelante trabajaría en la XEW. Javier Solís fue el mejor intérprete de este bolero ranchero que Solís cantara en la película Campeón del barrio en 1964. Cf. SACM, en línea.

24 «Esta vez ya no soporto / la terrible soledad; / yo no te pongo condición, / harás conmigo lo que quieras / bien o mal / Llévame, de ser posible, / hasta la misma eternidad, / donde perdure nuestro amor, / porque tú eres toda mi felicidad. / Llévame, si quieres, / hasta el fondo del dolor, / hazlo como quieras, / por maldad o por amor; / pero esta vez/ quiero entregarme a ti / en una forma total, / no con un beso nada más; / quiero ser tuyo, / sea por bien o sea por mal» (Bazán, 2001: 165).

${ }^{25}$ N. en La Habana y m. en la misma ciudad [en 1980]. Cf. Orovio, 1991: 260 y García, 2015, en línea.

${ }^{26}$ N. en Mérida Yucatán, el 22 de agosto de 1915. En 1935 llega a la ciudad de México y empieza a trabajar en la XEW como escritor y productor de programas. Su aportación a la cultura musical fue muy importante, pues compuso canciones por cuya emotividad, fineza y contenido, formaron parte de la llamada «Época de Oro de la canción romántica en México». Murió en la ciudad de México el 26 de noviembre de 1982. Cf. SACM, en línea. 
«Desvelo de amor» del portorriqueño Rafael Hernández Marín ${ }^{27}$, compuesta en 1937 (Bazán: 201) y cantada en tono de queja, se basa en tópicos corteses como la ausencia de la amada inalcanzable que es causa de los sufrimientos del enamorado, la dificultad del amante de vivir sin ella, así como en los males que le genera: insomnio, miedo a la pérdida del amor y, en suma, «un martirio sin cesar» ${ }^{28}$. En «Fiebre de ti» (ca. 1920-1930) del cubano Juan Manuel Arrondo Suárez ${ }^{29}$, bolero de tono melancólico y dramático, los males consisten en opresión mental, fiebre y ansiedad, producidos por una mala mujer, y lo sitúan ante el conflicto que entraña dejarla a pesar de su voluntad ${ }^{30}$.

«Esclavo y amo» (ca. 1960) de José Vaca Flores ${ }^{31}$, bolero ranchero interpretado por la voz apasionada de Javier Solís, está compuesto con base en el servicio de amor cortés y el tópico «morir de amor», empleados como recursos para enfatizar la pasión que abrasa al amante cuando la amada se ausenta; siente «morir mil veces» y vive en el conflicto de seguirla queriendo u olvidarla. Lo que me interesa destacar es que el amante se caracterice, al mismo tiempo, como esclavo y amo de su amada, de manera muy parecida a las paradojas propias del amante cortés dominado por la pasión amorosa ${ }^{32}$. Este bolero muestra que las penas generadas por la necesidad de amar también propician el deseo, y la expresión «morir de amor» se vuelve una expresión lexicalizada de exaltación amorosa.

En los siguientes boleros, «morir de amor» no es un tópico que desarrolle conceptos, sino que se convierte en una fórmula que en ocasiones manifiesta la máxima prueba de amor que el amante puede ofrecer. Es el caso de «Moriré de amor» (ca. 1940) del cubano Leopoldo Pérez Ulloa ${ }^{33}$, quien da voz de un amante adolorido por la pérdida de su amada, que se debate en el conflicto de olvidarla o recuperarla:

${ }^{27}$ N. en Aguadilla, Puerto Rico, 24 de octubre de 1892. A principios de los años 40 viajó a México y estudió en el Conservatorio Nacional de la Música, donde se graduó como maestro de armonía, composición y contrapunto. Murió en Puerto Rico el 11 de diciembre de 1965. Cf. Bailyn, 2015, en línea.

${ }^{28}$ «Sufro mucho tu ausencia, no te lo niego. / Yo no puedo vivir si a mi lado no estás. / Dicen que soy cobarde que tengo miedo / de perder tu cariño, de tus besos perder. / Yo comprendo que es mucho lo que te quiero, / no puedo remediarlo, ¿qué voy a hacer? / Te juro que dormir casi no puedo. / Mi vida es un martirio sin cesar / Mirando tu retrato me consuelo. / Vuelvo a dormir y vuelvo a despertar. / Dejo el lecho y me asomo a la ventana. / Contemplo de la noche el esplendor. / Me sorprende la luz de la mañana/ en mi loco desvelo por tu amor» (Bazán, 2001: 201).

${ }^{29}$ N. en Regla, La Habana, el 14 de mayo de 1914 y m. en Guanabacoa, el 16 de agosto de 1979. Su carrera comenzó en 1929. Cf. EcuRed, en línea.

30 «Este amor tan fatal / que amenaza mi mente, / esta fiebre de ti, / estas ansias vehementes. / Este calor de infierno / que me abrasa la frente, / perdonándote todo / tu pasado y tu presente.../ Pero no puede ser, no, / ir hacia ti sería / dejar en el camino de mi vida / los restos de mi hombría. / Arráncame, Dios mío, / esta idea tan morbosa / de desearte siempre/ sobre todas las cosas» (Orovio, 1991: 162-163).

${ }^{31}$ N. en Jocotepec, Jalisco, el 17 de marzo. A partir de 1961 empezó su carrera de compositor. La trayectoria de «Esclavo y amo» fue todo un éxito; después de haber sido interpretada por Javier Solís, y de que él estableciera su canon, fue cantada por muchos intérpretes. Cf. Mael Aglaia, 2014, en línea.

32 «No sé qué tienen tus ojos; / no sé qué tiene tu boca / que domina mis antojos / y a mi sangre vuelve loca. / No sé cómo fui a quererte / ni cómo te fui adorando. / Me siento morir mil veces/cuando no te estoy mirando. / De noche cuando me acuesto / a Dios le pido olvidarte /y al amanecer despierto / tan sólo para adorarte. / Qué influencia tienen tus labios / que cuando me besan tiemblo /y hacen que me sienta esclavo y amo del universo». Cf. Youtube, en línea.

${ }^{33}$ N. en La Habana el 21 de octubre de 1931. En 1939 se traslada a Catalina de Guines y en 1945 compone su primer bolero, «Amor entristecido». Murió el 6 de enero de 2003. Sus principales intérpretes fueron el dúo Guevara-Fulleda, Bienvenido Granda, Lino Borges, Antonio Machín, Celia Cruz, Celio González, José Tejedor y la Sonora Matancera. Cf. EcuRed, en línea. En la década de los cincuenta estrenó «En el balcón aquel» y «Mi súplica» (Orovio, 1991: 195). 
No puedo soportar esta tortura,

no resisto la pena y el dolor,

tu ausencia me ha llenado de amargura

y si no vienes pronto

me moriré de amor (Orovio, 1991: 196)

Pero, con mayor frecuencia, en nuestro corpus esta expresión tiene la función de suplicar o motivar el regreso de un amor perdido, o bien exaltar, lamentar, e incluso llorar la pérdida, a menudo en voces de amantes que oscilan entre renunciar a la amada o reconquistarla.

«Sombras» (ca. 1960) del argentino José María Contursi ${ }^{34}$, quien cantándola con «una macabra tendencia a la balada, consiguió que fuera un éxito en su país en los años sesenta ${ }^{35}$ », es la composición que expresa esa máxima prueba de amor. En este bolero memorable, el amante propone su inmolación y su muerte como prueba de amor a una dama esquiva que no le corresponde, por lo que «vive muriendo» de una manera desgarradora ${ }^{36}$. «Historia de un amor» (1955) del panameño Carlos [Eleta] Almarán ${ }^{37}$ que llegó a México por Luis Alcaraz y que le hizo a Libertad Lamarque merecer el Disco de Oro, emplea la expresión en voz de un amante que experimenta emociones contradictorias - sufre por la ausencia de la amada y a la vez reniega de que su suerte sea quererla - , y sin embargo cultiva el servicio de amor de su dama, pues en él encuentra la motivación para vivir ${ }^{38}$. De ahí que la ausencia de la amada lo lleve a imaginar que morirá:

¡Ay qué vida tan oscura!

Sin tu amor no viviré.

Las composiciones que lamentan y lloran la pérdida de un amor, plantean la muerte como solución a los padecimientos de un enamorado que ya ha intentado olvidar a su amada, como en «Moriré de amor» $(c a .1930)^{39}$ del cubano Leopoldo Ulloa ${ }^{40}$, o de

\footnotetext{
${ }^{34}$ N. el 31 de octubre de 1911 y muerto el 11 de mayo de 1972. «Tu nombre», de 1933 es su primera obra. Autor del famoso tango «Gricel». Cf. Nudler, en línea.

${ }^{35}$ De acuerdo con Bazán, «tango-canción», según otros: conoció sus mejores grabaciones como bolero en voz de Daniel Santos; con coros de trío, fue interpretado por Los Tres Reyes, y, como ranchera, por Javier Solís (2001: 249).

36 «Quisiera abrir lentamente mis venas, / mi sangre toda verterla a tus pies, / para poderte demostrar / que más no puedo amar / y entonces morir después. / Y sin embargo tus ojos azules, / azul que tienen el cielo y el mar, / viven cerrados para mí, / sin ver que estoy aquí / perdido en mi soledad. / Pude ser feliz / y estoy en vida muriendo, / y entre lágrimas viviendo / el pasaje más horrendo / de este drama sin final / Sombras, nada más, / entre tu vida y mi vida» (Ídem).

${ }^{37}$ N. en la ciudad de Panamá el 16 de mayo de 1918 en el seno de una familia rica que lo envió a estudiar a Málaga y posteriormente a Rhode Island (Bazán, 2001: 237). Murió en Panamá el 16 de enero de 2013. «El éxito de "Historia de un amor" se consolidó en la banda sonora del filme mexicano del mismo nombre. Rodado en 1956, tuvo como protagonistas a Emilio Tuero y a Libertad Lamarque, la célebre actriz y cantante, a quien el bolero le valió un disco de oro». Cf. EnCaribe, en línea.

38 «Ya no estás más a mi lado, corazón, / en el alma sólo tengo soledad / y si ya no puedo verte / ¿por qué Dios me hizo quererte, / para hacerme sufrir más?... / Siempre fuiste la razón de mi existir, / adorarte para mí fue religión... / Es la historia de un amor / como no habrá otro igual, / que me hizo comprender / todo el bien, todo el mal, / que le dio luz a mi vida / apagándola después» (Bazán, 2001: 237).

${ }^{39}$ No puedo soportar esta tortura, / no resisto la pena y el dolor, / tu ausencia me ha llenado de amargura / y si no vienes pronto / me moriré de amor (Orovio, 1991: 196).

${ }^{40}$ N. en La Habana el 21 de octubre de 1931 y murió el 6 de enero de 2003. En 1929 fue a vivir a Catalina de Guines y en 1945 compuso su primer bolero, «Amor entristecido». Entre sus intérpretes: Dúo Guevara Fullera, Enriqueta Almanza, Bienvenido Granda, Lino Borges, Antonio Machín, Celia Cruz, la Sonora Matancera, entre otros. Cf. EcuRed, en línea.
} 
un amante que muere por la ausencia de un amor imposible, pidiendo al viento el consuelo de su corazón, como «Vendaval sin rumbo (ca. 1940s)» ${ }^{41}$ del cubano José Dolores Quiñones $^{42}$.

A partir de esta revisión, podemos afirmar que el amor cortés sobrevivió a través de tres de los principales tópicos de la antigua lírica hispánica, los cuales, al adaptarse al contexto de la lírica popular hispanoamericana, por lo general se convirtieron en expresiones lexicalizadas orientadas a la conquista o bien, a la reconquista de la amada, excepto el servicio de amor, que sobrevive como tópico. Este suele tomar la forma de una declaración de amor, mientras que los males relacionados con la pasión amorosa se alejan de la tradición hispánica en tanto creencia o concepto, para formular declaraciones de amor, expresar las contradictorias emociones propias de la pasión amorosa, propiciar el deseo de la amada y exaltar la pasión en diferentes tonos. Asimismo, hemos visto que el tópico «morir de amor» se lexicaliza y adquiere diferentes funciones: suplicar o motivar el regreso de un amor perdido; o bien exaltar, lamentar o llorar la pérdida. Estas supervivencias abarcan en nuestro corpus desde los años 1900 hasta la década de los 60 del siglo XX, con mayor recurrencia entre 1920 y 1940 y participan de los variados estilos del género: canto cortés, bolero romántico, de cabaret y ranchero, cultivados en buena parte del continente americano: Cuba en primer lugar; México en segundo y Puerto Rico en tercero; y en menor proporción: Panamá y Argentina.

Durante la búsqueda de boleros con supervivencias de la antigua poética cortesana, encontré algunos donde esta convive junto con una visión del amor desgraciado, experimentada de manera negativa, en composiciones donde subyacen sentimientos de rebeldía, despecho y decepción de amantes que, aunque prometan o estén dispuestos a servir a la amada, no resisten las adversidades que conlleva la pasión y optan por abrigar sentimientos que van del rencor al odio. Naturalmente, «morir de amor» en los siguientes boleros de Cuba y México, compuestos entre las décadas de 1930 y 1950, carece de todo sentido, pues detrás de la rebeldía y el despecho se ocultan sentimientos de orgullo e impaciencia del amante que, desde luego, ya no se identifica plenamente con el antiguo trovador cortés, sino que se encuentra a medio camino entre la cortesía y la agresión.

En «Total» (1959) del cubano Ricardo García Perdomo ${ }^{43}$, el trovador expresa con sorna, desde la primera estrofa, que no responde a las expectativas del amante cortés, pues no tolera los desdeños de la dama ni está dispuesto a «morir de amor». Y si en la tercera estrofa revela irónicamente la vigencia de la poética cortesana que representan la dama esquiva y el amante rendido a un amor imposible, en la última el amante se niega a morir de amor en un acto de rebeldía ${ }^{44}$. «Ya no puedo amar» (ca. 1950) del cubano Rosendo

${ }^{41}$ «Vendaval sin rumbo... Llévate de mí las inquietudes / que me causan el desvelo/ por vivir soñando / con un imposible para el corazón... Vendaval sin rumbo / cuando vuelvas tráeme aromas de su huerto / para perfumar el corazón / que por su amor casi, casi, está muerto. / Dile que no vivo/ desde el día en que de mí apartó sus ojos, / llévale un recuerdo / envuelto en los antojos de mi corazón» (Orovio: 167).

${ }^{42}$ N. en Artemisa, Cuba el 19 de marzo de 1918. Hacia 1944 viajó a México, donde se desarrolló como guitarrista y compositor. Vive su éxito a finales de los años 50 y posteriormente viaja para recorrer los cafés europeos y finalmente se estableció en Toulouse, Francia, donde murió un 28 de marzo de 2008. Entre sus intérpretes: Javier Solís, Antonio Machín, Benny Moré, los Hermanos Bermúdez y José Dolores Quiñones. Cf. Cubanos Famosos, en línea.

${ }^{43}$ Nació en Santa Clara, Cuba, el 20 de abril de 1917. En 1942 se trasladó a La Habana y en 1959 salió al mercado «Total», resultando todo un éxito: en diciembre de ese mismo año ya había 40 versiones en las voces de Gatica, Olga Gillot, Fernando Álvarez y Bertha Dupuy. Salió de Cuba en 1991 para radicar en Miami, Florida. Cf. García, en línea.

44 «Pretendiendo humillarme pregonaste / el haber desdeñado mi pasión / y fingiendo honda pena imaginaste/ que moriría de desesperación... / Pensar que llegar a quererte / es creer que la muerte se pudiera 
Ruiz Quevedo ${ }^{45}$ es otra composición donde el protagonista se rehúsa a morir de amor. En ella plantea que la amada tardó mucho en arrepentirse de su traición y fue olvidada; el tiempo, sin embargo, le permite reflexionar acerca de su experiencia con cierta distancia $^{46}$.

En efecto, en el bolero hispanoamericano, las supervivencias del amor cortés no forman un conjunto homogéneo y sistemático, sino que constituye un complejo entramado en el que confluyen elementos contrarios, debido a que toda canción de amor obedece a procesos complejos y contradictorios que ponen en evidencia la tensión entre los sexos. Las mayores tensiones suelen encontrarse en el momento de la separación de los amantes, sobre todo cuando uno de ellos traiciona al otro. En este punto el bolero se convierte en la voz del despecho y la maldición, en vituperio hacia el amor perdido. En los boleros de despecho es precisamente donde se encuentran las aportaciones de la lírica americana, con sus mujeres malvadas y sus amantes cuya labilidad los lleva por caminos de una perdición diferente de la practicada por los antiguos trovadores.

«Traicionera» (ca. 1930-1940), del jalisciense Gonzalo Curiel Barba ${ }^{47}$, responde a la poética del amor cortés en la medida en que la dama se deja amar por el pretendiente y le da señales de tomar la iniciativa. Sin embargo, el poeta no responde al servicio de amor a la usanza cortesana, sino que su respuesta es el despecho, no entiende la esquivez de la dama, y lo interpreta como parte de su maldad y su carácter «traicionero ${ }^{48} »$. En «Puñalada trapera» (ca. 1950) del zacatecano Tomás Méndez Sosa ${ }^{49}$, el amante es «muerto de amor» no por una dama, sino por una mujer perversa y despiadada que lo ha engañado con dulces palabras, para luego «darle calabazas». Desde la perspectiva del poeta, su «muerte» es perpetrada a traición, por lo que no le queda más remedio que cantar

evitar. / Total, si no tengo tus besos / no me muero por eso, / yo ya estoy cansado de tanto besar. / Viví sin conocerte, puedo vivir sin ti» (Orovio, 1991: 155).

${ }^{45}$ N. en La Habana, Cuba, el 17 de octubre de 1918. M el 27 de junio de 2009. Compositor de canciones y boleros, así como de cha cha chás. La Asociación de Comentaristas Radiales le otorgó en 1955 el premio Wurlitzer por el éxito de «Los marcianos» y «Rico vacilón», boleros a los que debe su éxito internacional. Cf. EcuRed, en línea.

46 «Cuando perdí tu cariño / pensé que la vida terminaba en mí, / ya ves, he seguido viviendo/ ya afortunadamente me siento feliz. / El amor es traicionero, / doble filo de un puñal, / hoy que anhelas de nuevo mis besos/ sólo puedo decirte: ya no te puedo amar» (Orovio, 1991: 207).

${ }^{47}$ N. en Guadalajara, Jalisco el 10 de enero de 1904. En 1927 dejó la carrera de Medicina para radicar en la Ciudad de México. Inició como pianista en la XEW y posteriormente formó los grupos Ritarmelo (ritmo, armonía y melodía), Los diablos azules, Los caballeros de la armonía y Escuadrón del ritmo. Este llegó a ser muy famoso y marcó toda una época entre las orquestas de baile y como variedad principal en teatros de revista. Llevó su música a todo México, Estados Unidos, Brasil, Argentina y Chile. Además de música popular, también compuso música de fondo para películas, música sinfónica y conciertos para piano y orquesta. «Vereda tropical» es la canción con la que tuvo mayor éxito. Junto con Alfonso Esparza Oteo, Ignacio Fernández Esperón, Tata Nacho y Mario Talavera, entre otros, fundó el Sindicato Mexicano de Autores, Compositores y Editores de Música (SMACEM) y, posteriormente, de la Sociedad de Autores y Compositores de México. Murió el 4 de julio de 1958. En 2009 esta Sociedad le otorgó el reconocimiento Juventino Rosas. Cf. SACM, en línea.

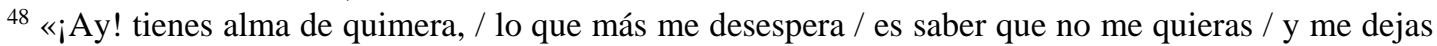
que te quiera. / ¡Ay! eres mala y traicionera, / tienes corazón de piedra / porque sabes que me muero / y me dejas que me muera. / Me miras y tu mirada / se mete dentro, dentro del alma. / Te miro y en mi mirada/ te está implorando mi corazón...» (Kuri Aldana, 1992, 2: 261).

${ }^{49}$ N. en Fresnillo, Zacatecas el 25 de julio de 1926. Tuvo éxito en los años 50, con canciones como «La luna dijo que no», «Que me toquen las golondrinas», «Cucurrucucú paloma», «Paloma negra», «Suspenso infernal». Intérpretes: Lucha Villa, María Dolores Pradera, Miguel Aceves Mejía, Pedro Infante y Javier Solís. Murió en la Ciudad de México el 19 de junio de 1995. Cf. SACM, en línea. 
su decepción, poniendo en evidencia la maldad de la mujer ${ }^{50}$. Estos son algunos ejemplos de los boleros situados entre la cortesía y el vituperio, y que seguramente sirven, tanto a quien canta como a quienes lo escuchan, como purga de los males causados por el amor, en noches de parranda, actividad que quizá podamos considerar como aportación americana, pues Francisco J. Santamaría incluye los vocablos parranda y parrandear en su Diccionario de general americanismos, definiéndola. Parranda es una «fiesta, jarana, por lo común con bebidas y mujeres, y por la noche», mientras que parrandear incluye la actividad de «andar a picos pardos» $(2, s v)$. Estos serían nuestros boleros «híbridos», debido a que el servicio de amor adquiere un valor ambiguo, por cuanto el amante puede prometerlo o desdeñarlo, volcando su agresión o vituperio a la amada.

Si los boleros donde sobreviven lexicalizados los tópicos más frecuentes del amor cortés de la antigua lírica hispánica se cantan en noches de serenata y en bailes orientados a la conquista amorosa, el bolero «híbrido» de despecho y vituperio funciona como purga y catarsis en noches de parranda a hombres y mujeres decepcionados y heridos de amor. Si los antiguos trovadores insistían en padecer el «mal de amores» hasta la mismísima muerte, en pos de la obtención de la amada, los poetas hispanoamericanos, con tres siglos de distancia, encontraron en la embriaguez una ruta para el olvido, aunque fuese momentáneo, del amor que se acabó.

La mayor parte de los boleros de despecho y vituperio remiten al conflicto que desemboca en la separación. Esta, en tanto hecho consumado o posible, desencadena un variado conjunto de respuestas del amante, que van desde estados depresivos en los que la agresión que producen se revierte sobre el sujeto que experimenta el abandono, hasta el odio y la violencia contra el objeto amoroso (Cf. Peza, 2001: 70), e incluso hacia sí mismo, como observamos en boleros donde la poética del amor cortés está ausente. Se trata de boleros de despecho y decepción propiciados por mujeres malas y traicioneras que se convierten en fuerte motivación para que los hombres ahoguen sus penas en el alcohol. Pongo por casos «Humo y espuma» del cubano Rolando Rabí (ca. 1956) ${ }^{51}$, bolero que canta la decepción amorosa de un hombre que, enloquecido, es asechado por el recuerdo y la imagen de una mujer y decide «ahogar» su pena en el alcohol ${ }^{52}$; «Entre espumas» $\left(1946^{53}\right)$, del también cubano Luis Marquetti ${ }^{54}$, es una variante del mismo tema: ante el abandono de una mujer, el amante encuentra en la bebida un remedio para el olvido $^{55}$; en «Lágrimas de hombre» ( $c a .1950$ s) del cubano Orestes Santos ${ }^{56}$, el amante ahoga sus penas de amor en noches de parranda ${ }^{57}$.

50 «Me estoy muriendo / y tú como si nada, / como si al verme / te alegraras de mi suerte, / ¿qué mal te hice / que no supiste perdonarme? / ¿qué mal te hice, / que me pagas con la muerte? / Me estoy muriendo / por tu culpa, por tu culpa; / si me engañabas con tu labia traicionera, / la puñalada que me diste/ fue trapera, / de esa se salva/ quien no tiene corazón; / qué mala de forma de pagarle a un corazón...» (Kuri Aldana, 1992, 1: 279).

${ }^{51}$ N. en Baire, el 17 de abril de 1916 y m. en Santiago de Cuba, donde tuvo mucho éxito durante la década de los años 1930 (Orovio, 1991: 171).

52 «Eres como una visión en mi locura / y en la copa que me embriaga / veo tu figura, quiero ahogar mi decepción / y por eso busco en la cerveza / mi tristeza dejar / para olvidar tu amor» (Orovio, 1991: 171).

${ }^{53}$ Ecured, en línea.

${ }^{54}$ N. en Alquízar, Cuba, el 24 de agosto de 1901. Sus boleros empezaron a escucharse durante los años 1940 (Orovio, 1991: 148).

55 «Si este amor nació de una cerveza / otra cerveza beberé para olvidar, / un querer que surge en una mesa / entre espumas se debe sepultar» (Ídem).

${ }^{56}$ Fue director de la agrupación musical de su nombre. Compositor de boleros muy exitosos desde finales de los años 1940 (Orovio: 158). N. en Vereda Nueva, La Habana el 9 de noviembre de 1923 y murió en el exilio en Florida, E.U., el 16 de julio de 2002. Cf. Vizcaíno, en línea.

57 «Llorando mis penas, como hacen los hombres, / voy de barra en barra, matando el dolor. / En copas de olvido y caricias fingidas / sin que nadie sepa mi inmenso penar» (Orovio, 1991: 158). 
Como muestra la revisión precedente, en el bolero hispanoamericano podemos distinguir boleros en los que sobrevive el tópico del servicio de amor y expresiones lexicalizadas provenientes de los principales tópicos del amor cortés que participan plenamente de la visión gozosa del amor (de 1900 a 1960 en Cuba, México, Puerto Rico, Panamá y Argentina). También hay boleros que he llamado «híbridos» porque se sitúan a medio camino entre el servicio de amor y el despecho y vituperio hacia la amada (entre 1930 y 1950 en México), los cuales aportaron a la tradición hispánica la purga y la catarsis de los males que aquejan a los amantes en el momento de la separación, así como las malas mujeres que poblaron el bolero ranchero y de cabaret. Esta revisión también permite la revaloración del bolero como género prolífico para la investigación de la poesía breve en Hispanoamérica en relación con sus influencias y antecedentes hispánicos, tales como el amor cortés. Por ello, no quiero dejar de anotar algunos de los temas y problemas que me fue sugiriendo esta investigación: a) estudiar las supervivencias del amor cortés a través de recursos como las metáforas relacionadas con la servidumbre, la cacería amorosa y la cárcel de amor; b) elaborar una cartografía de las supervivencias del amor cortés en el bolero hispanoamericano; c) investigar si la tradición bolerística es rica en composiciones «híbridas» y dar cuenta de sus autores, estilos, épocas y latitudes; d) contribuir al estudio de las supervivencias del amor cortés en otras formas y géneros hispanoamericanos como el romance y la poesía romántica del siglo XIX. Finalmente, espero que esta revisión anime a investigadores hispanoamericanos y españoles, jóvenes y consolidados, a colaborar en una empresa que se antoja colectiva y de muy largo aliento. 


\section{BIBLIOGRAFÍA}

BAILYN, Evan (2015): «Flores, Pedro», Música de Puerto Rico, Edna Frese (trad.). URL: <http://www.musicofpuertorico.com/index.php/artistas/pedro_flores>

BaILYN, Evan (2015): «Hernández Marín, Rafaél», Música de Puerto Rico, Edna Frese (trad.). URL:

http://www.musicofpuertorico.com/index.php/artistas/rafael_hernandez>,

BAZÁN, Rodrigo (ed.) (2001): Y si vivo cien años... Antología del bolero en México, México, Fondo de Cultura Económica.

CAstiLlo, Hernando del (2004): Cancionero General, 5 vols., Joaquín González Cuenca (ed.), Madrid, Castalia.

CiberCubA (2016). «Miguel Matamoros».

URL: 〈https://www.cibercuba.com/bio/musico/miguel-matamoros>

Cubanos Famosos (2013). «José Dolores Sotolongo Quiñones».

URL: <www.cubanosfamosos.com/jos\%C3\%A9-dolores-sotolongo-qui\%C3\% B1ones $>$

ECURED (s.f.): «Miguel Matamoros».

URL: <https://www.ecured.cu/Miguel_Matamoros>

ECURED (s.f.): «Osvaldo Farrés». URL:

<https://www.ecured.cu/Osvaldo_Farr\%C3\%A9s\#Obras_m.C3.A1s_famosas>,

ECURED (s.f.): «Juan Manuel Arrondo Suárez».

URL: <https://www.ecured.cu/Juan_Manuel_Arrondo_Su\%C3\%A1rez>

ECURED (s.f.): «Leopoldo Pérez Ulloa».

URL: <https://www.ecured.cu/Leopoldo_P\%C3\%A9rez_Ulloa>

ECURED (s.f.): «Rosendo Ruiz Quevedo».

URL: <http://www.ecured.cu/Rosendo_Ruiz_Quevedo>

ECURED (s.f.): «Luis Marquetti Marquetti».

URL: <https://www.ecured.cu/Luis_Marquetti_Marquetti>

ENCARIBE. ENCICLOPEDIA DE HISTORIA Y CULTURA DEL CARIBE (2016): «Carlos Eleta

Almarán». URL: 〈http://www.encaribe.org/es/article/carlos-eleta-almaran/558>

FRENK, Margit (2006): «Poesía de la aristocracia y poesía del pueblo en la Edad Media», en Poesía popular hispánica; 44 estudios, México, Fondo de Cultura Económica, pp. 42-57.

GARCíA, Roberto (2015): «Rubén Rodríguez», Musicuba.

URL: <http://musicubamyblo.blogspot.mx/2015/12/ruben-rodriguez.html>

GARCía, Roberto (2015): «Ricardo García Perdomo», Musicuba.

URL: <http://musicubamyblo.blogspot.mx/2015/10/ricardo-garcia-perdomo.html>

GonZÁLEZ CuENCA, Joaquín (2004): «Introducción», en Cancionero General, vol. 1,

Hernando del Castillo, de Joaquín González Cuenca (ed.), Madrid, Castalia, 27 y ss.

Kuri Aldana, Mario y Mendoza Martínez, Vicente (comps.) (1992): Cancionero popular mexicano, 2 vols, México, Consejo Nacional para la Cultura y las Artes / Dirección General de Publicaciones.

MAEl AGLAIA [seudónimo] (2014): «La cereza del pastel», Solismanía.

URL: <https://solismania.net/tag/jose-vaca-flores/>

NudLER, Julio (s.f.): «José María Contursi. Semblanza», Todo Tango.

URL: <http://www.todotango.com/creadores/biografia/60/Jose-Maria-Contursi > 
Orovio, Helio (ed.) (1991): 300 Boleros de Oro. Antología de obras cubanas, México, Presencia Latinoamericana / Instituto Nacional de Antropología e Historia / Unión de Escritores y Artistas de Cuba / Consejo Nacional para la Cultura y las Artes.

PEZA CASARES, María del Carmen de la (2001): El bolero y la educación sentimental en México, México, Universidad Autónoma Metropolitana, Unidad Xochimilco.

Santamaría, Francisco J. (1998): Diccionario General de Americanismos, 3 vols., Villahermosa, Gobierno del Estado de Tabasco.

Sociedad DE AutORES Y COMPOSITORES MEXICANOS [SACM] (2015): «Vicente Garrido», Biografías.

URL: <http://sacm.org.mx/biografias/biografias-interior.asp?txtSocio=08575>

SociedAd DE AutORES Y COMPOSITORES MEXICANOS [SACM] (2015): «Armando Manzanero», Biografías. URL: <http://sacm.org.mx/biografias/biografiasinterior.asp?txtSocio $=03623>$

SOCIEDAD DE AUTORES Y COMPOSITORES MEXICANOS [SACM] (2015): «Alvaro Carrillo Alarcón», Biografías. URL: <http://www.sacm.org.mx/biografias/biografiasinterior.asp?txtSocio $=08636>$

Sociedad DE Autores y Compositores MexicAnos [SACM] (2015): «Abelardo Pulido Buenrostro», Biografías.

URL: <http://www.sacm.org.mx/biografias/biografias-interior.asp?txtSocio= 02228>

Sociedad DE Autores y COMPositores MeXiCAnos [SACM] (2015): «José Antonio Zorrilla Monís», Biografías. URL:

$<$ http://www.sacm.org.mx/biografias/biografias-interior.asp?txtSocio=05053>

SOCIEDAD DE AUtORES Y COMPOSITORES MEXICANOS [SACM] (2015): «Gonzalo Curiel», Biografías.

URL: <http://www.sacm.org.mx/biografias/biografias-interior.asp?txtSocio=08006>

SociEdAD DE AuTORES y COMPOSITORES MeXICANOS [SACM] (2015): «Tomás Méndez Sosa», Biografías.

URL: <http://sacm.org.mx/biografias/biografias-interior.asp?txtSocio=08587>

Vizcaíno, María Argelia (2008): «Orestes Santos», Diccionario de talentos artísticos cubanos en el exilio.

URL: 〈http://www.mariaargeliavizcaino.com/m-DiccionarioTalentosCubanos_S.html>

YOUTUBE (2013): «Daniel Santos Amor [sic]».

URL: 〈https://www.youtube.com/watch?v=wW09a6CDdYE>

YoutuBE (2013): «Javier Solis Esclavo y Amo [sic]».

URL: <https://www.youtube.com/watch?v=xHSw0WiKhKQ>

Zavala, Iris (1991): El bolero. Historia de un amor, Madrid, Alianza Editorial.

Fecha de recepción: 29 de agosto de 2019

Fecha de aceptación: 1 de septiembre de 2019

\section{!}

